\title{
Polycystic Liver Disease
}

National Cancer Institute

\section{Source}

National Cancer Institute. Polycystic Liver Disease. NCI Thesaurus. Code C82833.

A usually asymptomatic hereditary disorder which is often associated with polycystic kidney disease. It is characterized by the presence of fluid-filled biliary cysts throug hout the liver. 